\title{
Initial impact of the new Australian tobacco health warnings on knowledge and beliefs
}

\author{
Ron Borland, David Hill
}

\begin{abstract}
Background-New health warnings and contents labelling on tobacco products were introduced in Australia in 1995.

Objective-To assess awareness of the new warnings at a time when a mix of packs with old and new warnings were being sold and on changes in relevant knowledge and attitudes from shortly before the implementation of the new warnings.

Design and subjects-Approximately 500 smokers and 500 non-smokers were surveyed in December 1994, before implementation of the new warnings. Similar numbers were also surveyed in May 1995, part-way through implementation. Respondents were selected by random-digit dialling of telephone numbers in Australia. Smokers were oversampled. In addition, 243 smokers from the initial survey were re-surveyed in May 1995.

Main outcome measures-Awareness of change to health warnings, knowledge of health warnings and tobacco smoke constituents, beliefs about the health effects of smoking, and perceived impact of the warnings.
\end{abstract}

Results-There was high awareness of the new warnings, particularly among smokers, with the increased size of the new warnings being the most salient feature. More than a third of smokers reported being affected by the warnings, with reductions in consumption and talking about warnings being the most common effects. Among smokers, there was an increase in knowledge about the main constituents of tobacco smoke. The number of types of health effects mentioned also increased as did the number of warnings correctly recalled. Overall beliefs about the six warning statements became stronger. Few changes were found for non-smokers. The knowledge and recall effects were replicated in the re-contact subsample, but the belief changes were not.

Conclusions-These results suggest the new health warnings are resulting in better informed smokers and thus suggest that informative health warnings can play an important role in better informing consumers.

(Tobacco Control 1997;6:317-325)

Keywords: Australia, health warnings, knowledge
Introduction

New health warnings and product labelling $\overrightarrow{0}$ were required on all cigarette packs manufactured in Australia after 1 January $1995 \vec{\omega}$ and on all imported cigarettes from 1 July $\overparen{\curvearrowright}$ 1995. (Imported cigarettes constitute a very small percentage of the Australian market.) The new warning label system was designed to be more noticeable and informative than that previously used. ${ }^{1}$ It requires printing one of six rotating warnings covering not less than $25 \%$ of the front of the pack at the top, with the top third of the back given over to an elaboration of the front-of-pack warning, plus the telephone number of an information line to call if further information is wanted (figure $1 \mathrm{a}, \mathrm{b}, \mathrm{c}$ ). The changes to content labelling required adding (to the information about tar, nicotine, and carbon monoxide levels) a brief elaboration of what they are and of their main health effects. Warnings and content information are required to be printed black on white.

The primary rationale for the introduction of new warnings was the consumers right to be well informed. ${ }^{2}$ From a public health viewpoint it was hoped additionally that warnings would encourage appropriate action based on better and more noticeable information about adverse effects of smoking. We hypothesised that smokers would notice the warnings more often, would read them, and as a result, would have increased understanding of issues covered. The focus of this report is on effects of the new health warnings on knowledge and attitudes of regular smokers, but data from non-smokers are reported where relevant.

There is little published research on the impact of the introduction of new health warnings on tobacco products. The introduction of the four previous Australian health warnings in $\sigma$ 1987 was associated with a rapid increase in $N$ their recall, ${ }^{3}$ but little change in that level of recall beyond the first months after implementation. ${ }^{14}$ Research on which the new warnings were grounded ${ }^{1}$ found that only about half of Australian smokers knew the tar? level of their usual brand, and knowledge of 0 nicotine and carbon monoxide levels (in particular) were far less. Research in the

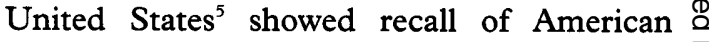
warnings at levels similar to those found in Australia, but American smokers' knowledge of the tar levels of their cigarettes ${ }^{6}$ was lower than in Australia.

\section{Methods}

RESPONDENTS

Two surveys were conducted, one in December 1994, about two weeks before the formal 


\section{SMOKING KILLS}

Government Health Warning

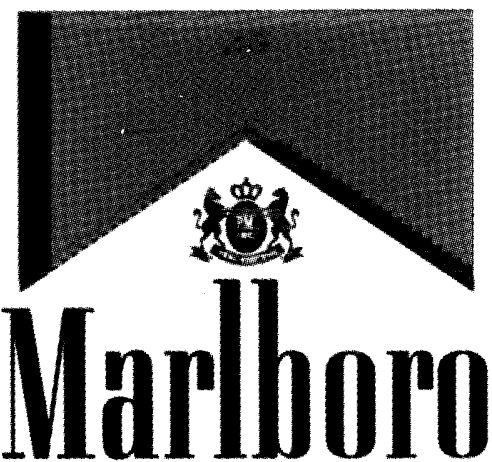

SIPER MIILD

(a)

Figure 1a An example of the Australian health warnings: front of pack.

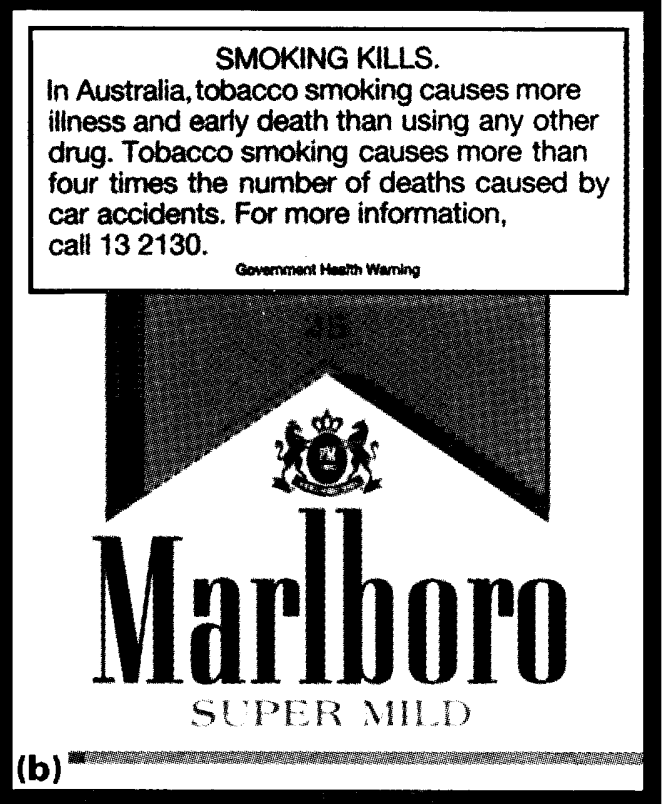

Figure $1 b$ Back of pack.

implementation date, and the second in May 1995, during the phase-in period for the new warnings. Smokers were deliberately oversampled because the impact of the warnings was likely to be felt most strongly by smokers.

Participants in the December 1994 baseline survey were 510 smokers and 525 non-smokers (183 ex-smokers and 342

The smoke from each cigarelte contains, on averaget: 8 miligrams or less of tar-condensed smoke oontiining mary chemicals, including some that cause cencer,

0.8 miligrams $\alpha$ less of nicotine-a poisonous end addictive drug: 10 miligrams or lass of carbon monoxide - a dasdy gas wich reduces the ability of blood to cany ongen (c)

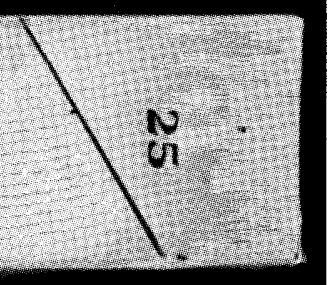

Figure 1c Contents labelling on one side. never-smokers). Of the non-smokers, $40 \%$ were men, and among smokers, 51\% were men. The May 1995 post-implementation (follow-up) survey participants were 512 smokers and 521 non-smokers (176 exsmokers and 345 never-smokers). Of the nonsmokers, $39 \%$ were men and, among smokers, $47 \%$ were men.

In May 1995, we also attempted to re-interview the 510 smokers in the baseline survey and were able to interview $243(48 \%)$. Of the remainder $11 \%$ refused to be re-surveyed and $41 \%$ were unable to be contacted. Those re-contacted were more likely to be women (57\%). They were also older than those not re-contacted $(26 \%$ aged 50 years or older, and $51 \%$ aged $30-49$ vs $18 \%$ aged 50 or older and $45 \%$ aged $30-49$ ). There were no significant differences in educational level or in a range of smoking-related variables: stage of change, previous quitting history, or mean daily cigarette consumption.

\section{PROCEDURES}

Respondents were selected by random-digit dialling of telephone numbers in Australia with quotas set for each state. Data collection was undertaken by a large market research company. Across both surveys, a third of attempts to call did not get through, and of those contacted, $33 \%$ refused to be interviewed, and a small number withdrew before the questioning was completed $(0.7 \%)$. This gives a response rate of $66 \%$ for those contacted, and $44 \%$ of attempts, if identified business numbers, people unable to communicate, and disconnected numbers are excluded. Response rates for both surveys were very similar (less than two percentage points difference on any estimate).

\section{QUESTIONNAIRES}

Questions in the two surveys (baseline and follow up) were largely identical, with a few extra questions asked at follow up, all but one of which were placed at the end of the survey. The ordering of questions in the survey was designed to have most of the general questions asked before any focused questioning about awareness of warning labels and their impact. Smoking status was defined with the question: "Do you smoke cigarettes at all or are you an ex-smoker or have you never smoked?" Also included were questions on cigarette consumption; an open-ended question on those illnesses respondents believed were caused by smoking; agreement or disagreement with 16 (14 for non-smokers) statements about smoking; an estimate of number of smokers out of 100 who die from smoking; perceptions of level of action of government and of the tobacco industry on informing people about smoking risks; smokers' estimates of their percentage chance of dying because of their smoking; smokers' perceptions of the relative risk of smoking in comparison with five other behaviours; quit-related activity; knowledge about contents of tobacco smoke; awareness of the new warnings; recall of new warnings; opinion about space and wording of 
new warnings; noticing warnings and thinking about dangers and effects on consumption; reported effects of the new warnings (follow up only); awareness of the Australian government's complementary publicity campaign (follow up only); and demographics. The demographics were sex, age (16-29, 30-49, $\geqslant 50$ ), educational level (year 10 or less, year 11-12, degree or diploma), country of birth (Australia, other English speaking, nonEnglish speaking), and whether in paid employment (fulltime, part-time, not employed). The order of questions was as listed above. Detail of the questions is provided below at appropriate places in the text.

\section{CONTEXT OF THE SURVEYS}

Over the nearly three years from the announcement of new warnings to the date of implementation, there was considerable publicity, both about the final form of the warnings and earlier stronger prototypes. ${ }^{4}$ In addition, at about the time of the baseline survey, the Commonwealth Department of Human Services and Health launched a small campaign promoting the new warnings. About two weeks before the survey, one manufacturer (WD \& HO Wills) announced that it was going to distribute packs with the new warnings ahead of the mandated deadline; however, we found no evidence that any were distributed before our survey. As a result of this activity and the newsworthiness of the changes, we might have expected some awareness of the impending new health warnings in the baseline survey but very little, if any, as a result of direct experience with the packs. Further, publicity subsequent to the baseline survey may contribute to any changes in knowledge of health effects found in the follow-up survey.

Surveys in most state capitals using unobtrusive observation of packs on display in retail outlets suggested that the phase-in of the new warnings took longer than anticipated.

Table 1 Characteristics of the two cross-sectional samples

\begin{tabular}{|c|c|c|c|c|}
\hline & \multicolumn{2}{|c|}{ Smokers } & \multicolumn{2}{|c|}{ Non-smokers } \\
\hline & $\begin{array}{l}\text { Baseline } \\
n=510\end{array}$ & $\begin{array}{l}\text { Follow up } \\
n=512\end{array}$ & $\begin{array}{l}\text { Baseline } \\
n=525\end{array}$ & $\begin{array}{l}\text { Follow up } \\
n=521\end{array}$ \\
\hline Women (\%) & 49 & 53 & 60 & 61 \\
\hline \multicolumn{5}{|l|}{ Age (years) (\%) } \\
\hline $16-29$ & 30 & 30 & 25 & 22 \\
\hline $30-49$ & 48 & 49 & 34 & $41^{\star}$ \\
\hline$\geqslant 50$ & 22 & 21 & 42 & 37 \\
\hline \multicolumn{5}{|l|}{ Education (\%) } \\
\hline$\leqslant$ Year 10 & 36 & 39 & 37 & 32 \\
\hline Year $11-12$ & 41 & 41 & 33 & 31 \\
\hline Higher & 23 & 20 & 30 & 37 \\
\hline Ex-smokers (\%) & NA & NA & 35 & 34 \\
\hline Mean cigarettes per day & 20.7 & 20.9 & NA & NA \\
\hline \multicolumn{5}{|l|}{ Stage $(\%)^{\dagger}$} \\
\hline Preparation & 19 & 22 & NA & NA \\
\hline Contemplation & 27 & 27 & NA & NA \\
\hline Precontemplation & 54 & 51 & NA & NA \\
\hline Quit attempt in last six months (\%) & 40 & 37 & 2 & 2 \\
\hline \multicolumn{5}{|c|}{ Last saw a cigarette packet close up (\%) } \\
\hline$\leqslant 2$ Days & NA & NA & 33 & 32 \\
\hline 3 Days to 3 months & NA & NA & 25 & 26 \\
\hline$>3$ Months/can't say & NA & NA & 42 & 42 \\
\hline
\end{tabular}

*Significant differences in distribution between surveys.

†Preparation: planning to quit in the next month;

Contemplation: not Preparation but seriously thinking about quitting in the next six months Precontemplation: not seriously thinking about quitting.

NA $=$ not applicable.
Around the time of our follow-up survey, packs with the new warnings were common on most popular brands, but rare (if present at all) on some other brands, and there was variability $\frac{0}{\partial}$ between retail outlets in which brands carried $\overrightarrow{\overrightarrow{0}}$ the new warnings. ${ }^{7}$ We have no accurate estimate of the proportion of packs sold with the new warnings, but estimate it at half or less.

The slower than anticipated implementation $\frac{\sigma}{\bar{\sigma}}$ of the warnings meant that it is possible that $\frac{\bar{m}}{7}$ some portion of the population (presumably $\stackrel{\mathbb{\Omega}}{\Omega}$ more non-smokers than smokers) had not been exposed to them at the time of the May $\vec{P}$ 1995 post-implementation survey. It also is probable that most smokers were smoking $\vec{\omega}$ from a mix of packs with old and new warnings at the time of the second survey. This lack of exposure would be likely to have the effect of diluting the overall impact of the warnings, at least on most of the indices used here. However, research on awareness of the previous health warnings after their implemen- $\vec{\nabla}$ tation revealed peak or near peak awareness $\mathbb{\mathbb { D }}$ within weeks of formal implementation when $\frac{\Phi}{3}$ packs with old warnings were still very $\underset{\mathbb{\Phi}}{0}$ prevalent. ${ }^{13}$

\section{DATA ANALYSIS}

Analyses were conducted separately for the cross-sectional and re-contact surveys. All analyses were conducted on unweighted data, for smokers and non-smokers separately, and $\mathbb{D}$ used the SPSS computer package.

For the cross-sectional surveys, differences between categorical variables were assessed by $\chi^{2}$ statistics, those for ordinal variables by the Mantel-Haenszel $\chi^{2}$ statistic, which is an index of trend across categories. Continuous or quasi-continuous variables were analysed with $t$ tests or analysis of variance. The results from the two cross-sectional samples are reported $\frac{0}{\partial}$ first. The results of the longitudinal subsample $\underline{\overrightarrow{0}}$ are then reported, usually briefly, unless the pattern of results is different to that from the 3 cross-sectional samples. Reference to the of longitudinal subsample is always explicit.

There were almost no missing data, but in 음 some cases respondents were unable to answer. For some variables “can't say” is treated as a separate category or combined with an appro- No priate other category. For other variables, these cases have been dropped from the analyses. In $N$ some cases, where these numbers have been $\omega$ small, this has not been explicitly noted in the text-but the number can sometimes be gleaned from sample sizes in tables or from $\stackrel{\Phi}{\mathcal{Q}}$ degrees of freedom for statistical tests.

A significance level of $\mathrm{P}<0.05$ is set throughout. Because of the large number of tests con- $\stackrel{\mathbb{Q}}{\mathbb{Q}}$ ducted it is likely that a small number of effects $\stackrel{\mathbb{Q}}{Q}$ are significant by chance. It is important to consider the overall pattern of results, rather 8 than focusing on each result in isolation. In many cases we have computed composite indices and have presented these along with $\stackrel{0}{\overrightarrow{0}}$ separate variables. Where the composite index is not significant, more caution should be exercised in interpreting significant results for component parts. 
Table 2 Unprompted reports of recent changes to health warnings on cigarette packs: cross-sectional follow-up sample

\begin{tabular}{lcc}
\hline Change to warning & $\begin{array}{l}\text { Smokers } \\
n=512(\%)\end{array}$ & $\begin{array}{l}\text { Non-smokers } \\
n=521(\%)\end{array}$ \\
\hline Bigger warning & 69.7 & 35.5 \\
More warnings & 31.8 & 14.0 \\
Top of pack placement & 20.3 & 7.1 \\
Black on white & 4.9 & 1.3 \\
Back of pack explanation & 5.5 & 0.4 \\
Side contents explanation & 5.3 & 0.6 \\
Stronger/more specific/different content & 4.9 & 4.2 \\
Information line number & 0.6 & 0.0 \\
Total aware & 91.4 & 50.9 \\
\hline
\end{tabular}

\section{Results}

CHARACTERISTICS OF SMOKERS AND

NON-SMOKERS

Smokers were more likely to be younger than non-smokers across both cross-sectional surveys (table 1). For non-smokers there was a marginally significant difference in the age distribution across surveys $(\mathrm{P}<0.05)$ with a greater proportion of 30-49 year olds in the follow-up sample. There were no other age or sex differences between surveys for either smokers or non-smokers.

Among the smokers across both crosssectional surveys, 93\% smoked factory-made cigarettes, and $20 \%$ smoked "roll your owns", including $7 \%$ who only smoked "roll your owns". Across both surveys, men smoked more cigarettes per day (23.0) than women (18.7), $(F=18.5$, df $=1,1015, \mathrm{P}<0.001)$. Consumption also varied as a function of age with 16-29 year olds smoking 17.1 per day, 30-49 year olds smoking 21.5 per day, and those 50 or older smoking 24.5 per day $(F=15.0$, df $=$ $2,1013, P<0.001)$. Forty-nine per cent ( $50 \%$ at baseline and $49 \%$ at follow up) smoked their first cigarette of the day within 30 minutes after waking.

Among the non-smokers, 32\% reported having seen a cigarette pack in the last two days, another $13 \%$ within a week, $13 \%$ within three months, and $28 \%$ longer than that, with another $14 \%$ unable to say. For subsequent analysis, the latter two categories were combined, as was the period from three days to three months.

Of the re-contact sample, $11 \%$ had quit at follow up and another $38 \%$ reported an unsuc- cessful quit attempt since the baseline interview.

AWARENESS OF CHANGES TO HEALTH WARNINGS Toward the end of both surveys, respondents were asked: "Are you aware of any recent changes to health warnings on cigarette packs?" In the cross-sectional samples, smokers' awareness increased from $28 \%$ at baseline to $91 \%$ at follow up $\left(\chi^{2}(1)=433.7\right.$, $\mathrm{P}<0.0001)$, and the awareness of non-smokers also increased from $24 \%$ to $51 \%\left(\chi^{2}(1)=78.2\right.$, $\mathrm{P}<0.0001)$. In the re-contact subsample, $90 \%$ reported awareness of the new warnings at follow up. Table 2 shows the reported content of the warnings among those aware of them.

At follow up, smokers aged under 50 were more likely to be aware of the new warnings (95\% for those under 30 and $94 \%$ for those 30-49) than older smokers $\left(80 \%, \chi^{2}(2)=24.4\right.$, $\mathrm{P}<0.0001)$. There were no effects for sex or education. Those born in non-Englishspeaking countries (79\%) were less aware than those from Australia (93\%) or other English-speaking countries $\left(95 \%, \chi^{2}(2)=\right.$ $15.7, \mathrm{P}<0.001)$. When age was controlled for, there was no effect for employment status.

\section{KNOWLEDGE OF HEALTH WARNINGS}

Respondents were then asked: "As far as you know, what do the health warnings on the front of cigarette packs say?" They were then prompted by the words, "Any others?" until they could not recall any more. It should be noted that recall in both surveys might have been inflated because respondents had previously been asked their beliefs about the six new warning statements among a number of other smoking-related statements; however, as recall of other (non-warning) statements was very low, responses are likely to reflect true memories. It can be seen from table 3 that at follow up nearly all (94\%) smokers were able to mention at least one warning, as were $56 \%$ of non-smokers. Slightly fewer at baseline got at least one correct. Correct was defined as mentioning any of the two warnings that were being phased out, the two retained, and the four new warnings.

Table 3 Recall of health warnings on cigarette packs: cross-sectional samples

\begin{tabular}{|c|c|c|c|c|}
\hline \multirow[b]{2}{*}{ Warnings } & \multicolumn{2}{|c|}{ Smokers } & \multicolumn{2}{|c|}{ Non-smokers } \\
\hline & $\begin{array}{l}\text { Baseline } \\
n=510\end{array}$ & $\begin{array}{l}\text { Follow up } \\
n=512\end{array}$ & $\begin{array}{l}\text { Baseline } \\
n=525\end{array}$ & $\begin{array}{l}\text { Follow up } \\
n=521\end{array}$ \\
\hline Smoking kills $(\%) \dagger$ & 6 & $55^{\star \star \star \star}$ & 7 & $25^{\star \star \star \star}$ \\
\hline Smoking when pregnant harms your baby $(\%) \dagger$ & 3 & $45^{\star \star \star \star}$ & 2 & $11^{\star \star \star \star}$ \\
\hline Smoking causes lung cancer $(\%) \$$ & 52 & $44^{\star}$ & 27 & 25 \\
\hline Your smoking can harm others $(\%) \dagger$ & 1 & $26^{\star \star \star \star}$ & 1 & $4^{\star \star \star}$ \\
\hline Smoking causes heart disease $(\%) \S$ & 46 & $35^{\star \star \star}$ & 13 & 13 \\
\hline Smoking is addictive $(\%) \dagger$ & 1 & $18^{\star \star \star \star}$ & 2 & 2 \\
\hline Smoking reduced your fitness $(\%) \ddagger$ & 36 & $10^{\star \star \star \star}$ & 8 & $5^{\star}$ \\
\hline Smoking damages your lungs $(\%) \ddagger$ & 19 & $6^{\star \star \star \star}$ & 3 & 3 \\
\hline Smoking is a health hazard (\%) & 27 & $10^{\star \star \star \star}$ & 46 & $30^{\star \star \star \star}$ \\
\hline Can't say (\%) & 2 & 3 & 20 & 21 \\
\hline Mentioned at least one (\%) & 87 & 94 & 43 & 56 \\
\hline Mean number mentioned & 2.0 & $2.7^{\star \star \star \star}$ & 1.2 & $1.4^{\star \star}$ \\
\hline Mean number of current warnings $\uparrow$ & 1.5 & 2.2 & 0.5 & 0.8 \\
\hline Average mentions for current warnings (\%) & 38 & 37 & 13 & 13 \\
\hline
\end{tabular}

tNew warning; $\neq$ warning being replaced; §retained warning; $\uparrow$ for baseline, the four legal in 1994; for follow-up, the six in the new warning system.

${ }^{\star} \mathrm{P}<0.05 ;{ }^{\star \star} \mathrm{P}<0.01 ;{ }^{\star \star \star} \mathrm{P}<0.001 ;{ }^{\star \star \star \star} \mathrm{P}<0.0001$. 
Table 4 Uncued knowledge about tar, nicotine, and carbon monoxide (CO)

\begin{tabular}{|c|c|c|c|c|}
\hline & \multicolumn{2}{|c|}{ Smokers } & \multicolumn{2}{|c|}{ Non-smokers } \\
\hline & $\begin{array}{l}\text { Baseline } \\
\text { (\%) } n=510\end{array}$ & $\begin{array}{l}\text { Follow up } \\
(\%) n=512\end{array}$ & $\begin{array}{l}\text { Baseline } \\
(\%) n=525\end{array}$ & $\begin{array}{l}\text { Follow up } \\
\text { (\%) } n=521\end{array}$ \\
\hline Tar is: any answer & 64 & 68 & 64 & 64 \\
\hline Tar is: acceptable answer & 48 & $55^{\star}$ & 50 & 49 \\
\hline Tar's effects: any answer & 74 & 75 & 77 & 73 \\
\hline Tar's effects: acceptable answer & 65 & 68 & 68 & 67 \\
\hline Nicotine is: any answer & 63 & 69 & 68 & 68 \\
\hline Nicotine is: acceptable answer & 46 & $54^{\star}$ & 51 & 53 \\
\hline Nicotine effects: any answer & 74 & 76 & 76 & 78 \\
\hline Nicotine effects: acceptable answer & 52 & 57 & 51 & 52 \\
\hline $\mathrm{CO}$ is: any answer & 70 & 73 & 79 & 77 \\
\hline CO is: acceptable answer & 61 & $67^{\star}$ & 70 & 69 \\
\hline CO effects: any answer & 62 & 69 & 75 & 72 \\
\hline CO effects: acceptable answer & 55 & $63^{\star}$ & 68 & 62 \\
\hline
\end{tabular}

$\star \mathrm{P}<0.05$.

See text for definition of "acceptable" answer.

At follow up, as compared with baseline, more smokers mentioned a warning $\left(\chi_{\mathrm{M}-\mathrm{H}}^{2}=\right.$ $11.7, P<0.001)$ and the mean number mentioned was also higher $(t(1020)=8.74$, $P<0.0001$; see table 3$)$. Similar results were found for non-smokers $\left(\chi_{\mathrm{M}-\mathrm{H}}^{2}=18.7\right.$, $\mathrm{P}<0.0001$, and $t(1044)=2.67, \mathrm{P}<0.01$ respectively).

Among smokers at follow up, recall of the six new warnings was inversely related to age, $\left(F_{(2,509)}=65.4, P<0.0001\right)$. Controlling for age, there was a small effect for education with the better educated recalling slightly more $\left(\mathrm{F}_{(2,503)}=\right.$ $3.2, \mathrm{P}<0.05)$, and for $\operatorname{sex}\left(\mathrm{F}_{(1,506)}=5.4, \mathrm{P}<0.05\right)$ with women recalling slightly more than men, but no effect for country of birth or workforce participation. Among non-smokers, recency of seeing a pack was linearly related to recall $\left(F_{(2,518)}=36.8, P<0.0001\right)$, as was age $\left(F_{(2,518)}=\right.$ $69.5, \mathrm{P}<0.0001)$.

The average percentage of smokers recalling each of the four old warnings at baseline was $38 \%$ and this level was maintained for the six new warnings at follow up $(37 \%)$, indicating that each of the new warnings is as salient as the old ones. A similar result, albeit with lower levels of recall, was found for the non-smokers (see table 3 ). These findings suggest that the move from four to six warnings has produced an increase of about $50 \%$ in the amount of salient warning information available to people.

In the re-contact sample of smokers, warnings recalled increased from 1.9 at baseline to 2.8 at follow up $(\mathrm{P}<0.0001)$, a pattern which was consistent with the cross-sectional data. Analysis of this group as a function of whether they had quit at follow up revealed a significant interaction, with the number recalled increasing more in the continuing smokers (1.9-2.8 warnings), whereas recall in the quitters was unchanged $\left(F_{(1,241)}=7.9, P<0.01\right)$. This suggests that the increase in warnings recalled was related to exposure to those warnings, if we assume that those who have quit have less exposure.

\section{KNOWLEDGE OF CONSTITUENTS OF TOBACCO} SMOKE

In both surveys, all respondents were asked a series of questions about the information on the contents of cigarette smoke which is contained on one side of cigarette packs.

\section{Tar}

The first question was: "Cigarette packs $\stackrel{\vec{F}}{\stackrel{0}{ }}$ contain information about tar content. Can $\vec{\Rightarrow}$ you tell me in your own words what tar is?" 웅 Responses were categorised into those that showed some understanding of what tar in $\frac{\bar{D}}{\bar{D}}$ tobacco is (brown/black stuff, mix of $\frac{\Phi}{\Phi}$ chemicals), called "acceptable" answers here, $\stackrel{2}{0}$ and those that did not show an understanding (for example, nicotine, something they put on $\overrightarrow{0}$ roads). Overall, smokers were marginally more $\vec{\overrightarrow{ }}$ likely to give at least one acceptable answer at follow up than at baseline, but among $\stackrel{\vec{?}}{\overrightarrow{0}}$ non-smokers there was no difference (table 4). The most common responses by smokers at $\stackrel{\vec{\omega}}{\omega}$ follow up were "brown or black stuff” by $22 \%$; $\vec{V}$ "gunk, ooze, or sticky stuff" by $19 \%$; "mix of 음 chemicals/poison" by $14 \%$; and "residue/ byproduct" by $10 \%$. The only change between surveys in specific responses was a decline in $\underset{\mathbb{D}}{\mathbb{D}}$ smokers incorrectly reporting tar as nicotine $\frac{\mathbb{2}}{3}$ (baseline $6 \%$ vs follow up $3 \% ; \chi_{\mathrm{M}-\mathrm{H}}^{2}=4.9 ;$ 迎 $\mathrm{P}<0.05)$.

Respondents were then asked what the $\overrightarrow{0}$ effects of tar on a smoker are, and about $75 \%$. were able to give an answer, of which most were acceptable (see table 4 ). There were no significant differences in providing acceptable $\bar{O}$ responses between baseline and follow up for $\frac{0}{D}$ either smokers or non-smokers. The responses $\stackrel{\square}{\Rightarrow}$ most often given by smokers at follow up were $\overrightarrow{\overrightarrow{0}}$ that tar clogs up the lungs (by 50\%) and harms the lungs (by $24 \%$ ).

Smokers were then asked the tar level of their regular brand. At baseline, $72 \%$ were able to provide a plausible answer, as were $71 \%$ at follow up. For the factory-made cigarettes, the cross-tabulation of their report of the tar level o of their brand with the known tar level of the brand they say they usually smoke indicates that at both baseline and follow up, $52 \%$ knew 3 . their tar band, a figure virtually identical to that found several years earlier. ${ }^{1}$ Young people were $\frac{}{3}$ more likely to know (57\% of 16-29 year olds 을 compared with $43 \%$ of those aged 50 or older). Among those who knew their tar band, knowledge of the effects of tar was greater at follow up than at baseline $\left(\chi_{\mathrm{M}-\mathrm{H}}^{2}=5.3, \mathrm{P}<0.05\right)$; $\sigma$ whereas for those not aware of their tar band, $N$ levels of knowledge were equivalent.

\section{Nicotine}

Respondents were then asked a similar set of $\stackrel{\mathbb{\Phi}}{\mathbb{S}}$ questions about nicotine content and about 0 two-thirds provided a response (see table 4 ). Among smokers, there was an increase in the $\stackrel{\square}{\square}$ percentage giving an acceptable answer across $\stackrel{\mathbb{Q}}{\stackrel{2}{2}}$ surveys, but no change among non-smokers. The main responses given by smokers at follow up were a drug (by $42 \%$ ) and a poison (by융 $11 \%)$. A greater proportion of smokers at follow up $(42 \%)$ than baseline (34\%) mentioned that nicotine is a drug $\left(\chi_{\mathrm{M}-\mathrm{H}}^{2}=7.4\right.$; $P<0.01)$. A similar increase was found for nonsmokers. There was also an increase for nicotine being a poison for smokers, with $6 \%$ 
saying it was so at baseline, and $11 \%$ at follow up $\left(\chi_{M-H}^{2}=6.7 ; \mathrm{P}<0.01\right)$.

There were no significant differences between baseline and follow up in the percentage giving an acceptable response as to what the effects of nicotine are for either smokers or non-smokers (see table 4). The most common responses of smokers at follow up were that nicotine is addictive (by $54 \%$ ), is bad for you $(13 \%)$, and stains fingers $(9 \%)$. Smokers at follow up were significantly more likely to mention "addictive" (54\%) as an effect of nicotine than at baseline $(47 \%)\left(\chi_{\mathrm{M}-\mathrm{H}}^{2}=4.8\right.$; $\mathrm{P}<0.05)$.

At baseline, $30 \%$ of smokers were able to give a plausible answer to the question about the nicotine level of their regular brand, (within the actual range of levels), compared with $28 \%$ at follow up. The difference was not significant. Unlike for tar content, we had no accurate data on actual nicotine levels. Levels of actual knowledge are likely to be less than those reported. It is likely that only a small minority are actually aware of the nicotine level of their brand.

\section{Carbon monoxide}

There was a significant increase in the percentage of acceptable responses as to what carbon monoxide is between surveys among smokers ( $61 \%$ vs $67 \%$ ), but not among non-smokers (see table 4). The most common responses for smokers at follow up were, a gas $(57 \%)$ and a poison $(22 \%)$. More smokers at follow up said that carbon monoxide is a gas $(57 \%)$ than at baseline $(45 \%) \quad\left(\chi_{\mathrm{M}-\mathrm{H}}^{2}=16.0 ; \quad \mathrm{P}<0.0001\right)$. There was a reduction in mentions of car exhaust or engine fumes by smokers, from $9 \%$ at baseline to $4 \%$ at follow up $\left(\chi_{\mathrm{M}-\mathrm{H}}^{2}=12.1\right.$; $\mathrm{P}<0.001$ ).

Among smokers there was a significant increase in knowledge of the effects of carbon monoxide (see table 4), with a trend for non-smokers $\left(\chi_{\mathrm{M}-\mathrm{H}}^{2}=3.4, \mathrm{P}=0.07\right)$ towards reduced knowledge. The most common answers for smokers at follow up were, reduces oxygen uptake $(31 \%)$ and deadly $(21 \%)$. At follow up, a drop for carbon monoxide being deadly was found for both smokers and non-smokers: $27 \%$ at baseline to $21 \%$ at follow up for smokers $\left(\chi_{\mathrm{M}-\mathrm{H}}^{2}=5.0 ; \mathrm{P}<0.05\right), 32 \%$ at baseline and $23 \%$ at follow up for non-smokers $\left(\chi_{M-H}^{2}=10.5 ; P<0.01\right)$. For smokers, there was a significant increase in mentions of carbon monoxide reducing oxygen uptake, from $16 \%$ at baseline to $31 \%$ at follow up $\left(\chi_{\mathrm{M}-\mathrm{H}}^{2}=31.0\right.$; $\mathrm{P}<0.0001$ ).

At baseline, $24 \%$ of smokers were able to give a plausible carbon monoxide level for their regular brand compared with $28 \%$ at follow up, a non-significant difference (as with nicotine, we have no data on actual levels).

\section{Re-contact sample}

In the re-contact sample there was no significant change in knowledge of tar, a significant increase in knowledge of what nicotine is $(P<0.005)$, a trend for increased knowledge of nicotine's effects $(p=0.07)$, and significant increases in knowledge of what carbon monoxide is $(\mathrm{P}<0.01)$ and what its effects are
$(\mathrm{P}<0.005)$. The pattern is similar to that described above for the cross-sectional analysis.

PERCEIVED IMPACT OF THE WARNINGS In the follow-up survey a number of perceivedimpact questions were asked towards the end of the interview. Two of the nine recent ex-smokers from the non-smoker subsample and $16 \%$ of the 188 smokers who had tried to quit recently said the warnings contributed to their decision to quit. When those who were not aware of the new warnings were dropped from the analysis, two of eight ex-smokers and $18 \%$ of smokers reported influence.

Smokers were also asked if the new warnings had any effect on the number of cigarettes they smoke per day. Less than $1 \%(0.8 \%)$ said they now smoked more as a result, $1.4 \%$ said they had had a temporary effect in reducing consumption, and $13.5 \%$ said they now smoked less because of the warnings. When asked (earlier in the survey) about reported consumption change in the last two months, $19 \%$ claimed to have reduced consumption. This was not significantly different from the $16 \%$ reporting this at baseline, suggesting that much of any consumption reduction, if it was real, would probably have happened anyway. Indeed, in the cross-sectional sample there was not a significant change in reported consumption, although in the longitudinal subsample, there was (from 22.0 to 20.5 cigarettes per day, $\mathrm{P}<0.05)$.

Smokers who were aware of the new health warnings were then asked if they had avoided buying packs with any of the health warnings on them, and $6 \%$ said "yes". These were mainly younger smokers. They were then asked for other effects on them or on other smokers. Responses included talking about the warnings $(16 \%)$, negative (for example, don't like them, they worry me, $9 \%$ ) and positive comments (for example, think they are better, they will affect smoking, $7 \%$ ), use or awareness of stickers to obscure the warnings $(2 \%)$, turning the pack face down to avoid the front-of-pack warning $(2 \%)$, and other avoidance of the warnings $(3 \%)$. Overall, $36 \%$ of smokers reported at least one of the above effects. As most of the negative comments relate to intended or desirable aspects of the changes, the net effect is positive from a public health viewpoint.

Smokers were also asked if they had thought about or called the telephone information line promoted on packs. Only one respondent had called the line $(0.2 \%)$, and another $5 \%$ of all smokers had thought about it.

The pattern of responses among the re-contact sample of smokers was very similar to that in the cross-sectional sample for all these indices of reported impact.

\section{MORE GENERAL HEALTH BELIEFS}

To assess the salience of health concerns about smoking, all respondents in both surveys were asked: "In your opinion, are there any illnesses caused by smoking?". Those saying "Yes" were asked: "Which illnesses are caused by 
Table 5 Salient beliefs about illnesses caused by smoking

\begin{tabular}{|c|c|c|c|c|}
\hline \multirow[b]{2}{*}{ Category of illness } & \multicolumn{2}{|c|}{ Smokers } & \multicolumn{2}{|c|}{ Non-smokers } \\
\hline & $\begin{array}{l}\text { Baseline } \\
n=510\end{array}$ & $\begin{array}{l}\text { Follow up } \\
n=512\end{array}$ & $\begin{array}{l}\text { Baseline } \\
n=525\end{array}$ & $\begin{array}{l}\text { Follow up } \\
n=521\end{array}$ \\
\hline Cancer (\%) & 52.9 & $61.1^{\star \star}$ & 74.1 & $79.3^{\star}$ \\
\hline Circulatory (\%) & 33.3 & $40.4^{\star}$ & 36.8 & 36.5 \\
\hline Respiratory (\%) & 42.9 & 39.6 & 51.0 & 53.9 \\
\hline Coughs and 'flu (\%) & 5.9 & 7.8 & 3.2 & 4.4 \\
\hline Pregnancy-related (\%) & 0.4 & $3.5^{\star \star \star}$ & 1.7 & 1.7 \\
\hline Mean number of illness categories mentioned & 1.35 & $1.53^{\star}$ & 1.67 & 1.76 \\
\hline
\end{tabular}

smoking?" and prompted with "Any others?" until unable to give more. As can be seen from table 5 , in both surveys smokers were slightly less likely to report most of the illnesses identified than were non-smokers. Illnesses mentioned were categorised into five groups: cancer, circulatory problems (such as heart disease, stroke), chronic respiratory problems (such as emphysema), colds and 'flu, and pregnancy-related. At follow up, smokers identified significantly more disease groups than they did at baseline ( 1.53 vs $1.35, t=2.38$, $\mathrm{P}<0.05)$ but there was no effect for non-smokers $(P=0.10)$. Separate analyses indicated that, at follow up, smokers were more likely to mention cancer (largely due to increased mentions of "cancer unspecified"), circulatory problems (due to an increase in "heart disease"), and problems in pregnancy. For non-smokers, mentions of cancer increased between surveys $(P<0.05)$.

In the re-contact sample of smokers, there was also a significant increase in the number of illness groups mentioned ( 1.31 to $1.52, t=3.1$, $\mathrm{df}=242, \mathrm{P}<0.005)$. The pattern of specific illness mentions was also similar.

Smokers were then read 16 statements and non-smokers 14, with 13 statements being common, although in two items there were minor wording differences (table 6). Each statement was an index of attitude and/or knowledge in respect of smoking and a closed five-point "strongly agree" (scored 5) to "strongly disagree" (scored 1) response format was used (except for some negatively worded health effect questions where scoring was reversed). A sixth option "can't say" was re-coded for statistical analysis to the midpoint (3) to be equivalent to "neither agree nor disagree". The items included the six new warnings statements (or very similar versions).
There were also six statements about other $\overrightarrow{0}$ health effects: that smoking causes emphy- $\vec{\overrightarrow{ }}$ sema; that "It would improve my health if $I \stackrel{\omega}{\sigma}$ quit smoking" (smokers only); that smoking $\stackrel{\vec{?}}{\mathrm{P}}$ low-tar cigarettes is safe; and three statements suggesting that the dangers of smoking are $\vec{\omega}$ exaggerated or in relative terms are not as $\vec{V}$ important as other risks. There were also four 음 positive statements about smoking: that smok- $\rightarrow$ ing helps cope with stress, that it is enjoyable, $\underset{\mathbb{D}}{\square}$ that they would miss smoking if they gave up $\overparen{\mathbb{D}}$ (smokers only); and that they liked the look of $\frac{3}{0}$ the pack their cigarettes come in (smokers), or $\mathbb{\mathbb { Q }}$ that cigarette packs are attractive (non- $\vec{\theta}$ smokers). Order of presenting the items was $\stackrel{\theta}{v}$ systematically varied to minimise any order 0 effects.

There was reasonably strong acceptance in both surveys of the statements from the health warnings (the first six statements); that is, $\stackrel{\mathbb{Q}}{\mathbb{2}}$ means were well above 3.0 (see table 6 ). The $\overrightarrow{\overrightarrow{0}}$ percentage of smokers disagreeing with at least $\frac{3}{3}$ one fell from $46 \%$ at baseline to $40 \%$ at follow up.

Non-smokers were far more likely to endorse statements identifying harm done by smoking. By contrast, smokers were strikingly more likely to see benefits (stress reduction, enjoyment) in smoking than non-smokers. There is also a widespread belief, particularly among smokers, that the harm of smoking is exaggerated or is less than the harm from other causes. For example, at follow up, $50 \%$ of smokers agreed with the statement that the dangers of smoking have been exaggerated. There was also ambivalence among smokers: while $74 \%$ strongly agreed they would miss smoking if they gave up, $89 \%$ agreed that doing so would improve their health and $93 \%$ agreed that it was addictive.

Table 6 Mean (SD) of response to knowledge and attitude items

\begin{tabular}{|c|c|c|c|c|}
\hline \multirow[b]{2}{*}{ Statement } & \multicolumn{2}{|c|}{ Smokers } & \multicolumn{2}{|c|}{ Non-smokers } \\
\hline & $\begin{array}{l}\text { Baseline } \\
n=510\end{array}$ & $\begin{array}{l}\text { Follow up } \\
n=512\end{array}$ & $\begin{array}{l}\text { Baseline } \\
n=525\end{array}$ & $\begin{array}{l}\text { Follow up } \\
n=521\end{array}$ \\
\hline 1. Smoking causes lung cancer & $4.05(1.27)$ & $4.11(1.19)$ & $4.66(0.80)$ & $4.66(0.77)$ \\
\hline 2. Smoking kills & $3.70(1.37)$ & $3.75(1.36)$ & $4.51(0.94)$ & $4.45(0.94)$ \\
\hline 3. Smoking causes heart disease & $3.88(1.25)$ & $4.03(1.12)$ & $4.42(0.90)$ & $4.31(0.98)$ \\
\hline 4. (Your)t Smoking can harm others & $3.49(1.44)$ & $3.78(1.24)^{\star \star}$ & $4.58(0.85)$ & $4.52(0.93)$ \\
\hline 5. Smoking is addictive & $4.65(0.94)$ & $4.76(0.66)^{\star}$ & $4.80(0.63)$ & $4.80(0.61)$ \\
\hline $\begin{array}{l}\text { 6. Smoking when pregnant harms (your) } f \text { the baby } \\
\text { Scales }\end{array}$ & $3.99(1.28)$ & $4.02(1.22)$ & $4.56(0.83)$ & $4.54(0.83)$ \\
\hline Warning statements (1-6) & $3.96(0.91)$ & $4.07(0.82)^{\star}$ & $4.59(0.57)$ & $4.54(0.61)$ \\
\hline Non-warning health effects & $3.54(0.87)$ & $3.56(0.86)$ & $4.15(0.78)$ & $4.14(0.76)$ \\
\hline Positives of smoking & $3.66(0.78)$ & $3.68(0.74)$ & $3.26(0.83)$ & $3.19(0.75)$ \\
\hline
\end{tabular}

†Slightly different wording for smokers and non-smokers.

$\star P<0.05$ baseline to follow up.

$\star \star \mathrm{p}<0.01$. 
For the 16 belief questions for smokers taken individually, only two showed significant changes between surveys. The beliefs that "Smoking is addictive" $(t=2.31, \mathrm{df}=1020$, $\mathrm{P}<0.05)$ and "Your smoking can harm others" $(t=3.47, \mathrm{df}=1020, \mathrm{P}<0.01)$ became stronger between surveys. Among non-smokers, the only effect was that they were marginally less likely to agree at follow up that the design of cigarette packs was attractive $(t=1.97, \mathrm{df}=$ 1044, $\mathrm{P}<0.05$ ).

When the six warning statements were combined, a significant increase in agreement was found for smokers $(t=2.11, \mathrm{df}=1020$, $\mathrm{P}<0.05)$, but not for non-smokers. There were no effects for the non-warning health effect questions or for the positives of smoking items. To check whether the increased agreement with the warnings was a specific effect, a two-way analysis of variance was used to compare change in warning beliefs relative to nonwarning health beliefs. The expected interaction was significant for smokers $(F=$ $5.38, \mathrm{df}=1,1020, \mathrm{P}<0.05)$. There was a small but significant increase in agreement with the warning beliefs over and above any changes in non-warning health beliefs. We also checked to see whether this effect held up when we controlled for age and sex. The effect remained $(F=4.7, \mathrm{df}=1,1021, \mathrm{P}<0.05)$. There was no effect of sex, a strong age effect $(F=67.9, \mathrm{df}=$ $2,1021, P<0.0001)$, and no interaction. In both surveys, younger people were much more likely to agree with the warning statements than older people. There were similar effects for stage of change. Those closer to quitting accepted health effects more strongly and were less likely to believe in benefits of smoking, but again there was no interaction between stage of change and survey.

For the re-contact sample of smokers there were no significant differences between surveys for individual items or for the three scales, nor any evidence of trends. That is, the changes found in the cross-sectional sample were not replicated here.

\section{Discussion}

The results of this study indicate that about five months after the new warnings were introduced, at a time when a mix of packs with the new and old warnings were available to smokers, there were high levels of awareness of the new health warnings on cigarette packs at least among smokers. Most of those aware correctly reported at least one element of the new warnings, with increased size by far the most prominent. Some aspects of the new labelling requirements were not as prominent as might have been hoped; mention of the back-of-pack information and side-of-pack contents information was low. This may have been in part because we asked about recent changes to health warnings rather than recent changes to labelling requirements, but also is probably partly due to some of the other elements being even more salient and perhaps to limited exposure.

At the time of surveying, some people remained unaware of the new warnings.
Among smokers, lack of awareness could be because they had never bought or seen a pack with the new warnings. It is also possible that some may have used packs with the new warnings, but have never noticed them. This latter explanation is more likely to apply to lack of awareness of components of the new warning regimen, and may account for the small number who said they were aware of the warnings, but were unable to say what the changes were. Among non-smokers, awareness of the new warnings was strongly related to recency of exposure to cigarette packs.

Recall of the new warnings was considerable in the follow-up survey. The high recall of warnings shortly after implementation is similar to that reported for the previous health warnings. ${ }^{2}$ Two of the new warnings, "Smoking kills" and "Smoking in pregnancy harms your baby", were the most frequently recalled warnings among smokers and the ones seen as having the greatest impact. The number of warnings recalled increased by about $50 \%$ between surveys, probably due to the greater number of warnings, but perhaps partly because recall occurred after participants had rated their agreement with both warning and other statements. If recall is greater, it suggests that smokers have more warning information uppermost in their minds, which should act as a stimulus for increasing the strength of beliefs about smoking-related harm.

Many smokers still lack even a basic understanding of the major constituents of tobacco smoke or of their potential health effects, even though there was a small increase in knowledge at follow up. However, there was no improvement in smokers' knowledge of the levels of the constituents in the cigarettes they usually smoke, knowledge that has not changed since $1991 .{ }^{1}$ It is possible that knowledge will increase further as more people come to read and assimilate the extra information that is provided.

About a third of the smokers reported immediate responses to the new warnings. Some reported avoiding buying packs with the new warnings, smoking fewer cigarettes as a result, or just talking about the smoking issue. Although almost all of these effects were positive (in terms of smoking control), a few people reported smoking more as a result, or thinking the warnings may be counter-productive, or both. The rarity of reported negative effects is reassuring.

For the most part, the results on change from the cross-sectional samples were mirrored by the longitudinal subsample, but there were differences. The longitudinal subsample reduced consumption but did not change warning-related beliefs. The disparity between the two substudies could be due to a number of factors. It could reflect differences between the re-contact subsample and the follow-up cross-sectional sample, or it could be due to reactive effects of having been previously surveyed on these issues. Evidence that the effects on beliefs found in the cross-sectional survey might be due to the new 
warnings are that the changes in beliefs were specific to new warnings, and occurred over and above any changes in smoking-related health beliefs not directly targeted by the new warnings. That the effects were also restricted to smokers, who have greater exposure, is further evidence of a specific effect.

Why was the difference in beliefs not seen in the re-contact sample? Re-contacted respondents exhibited the same or very similar levels of awareness of the new warnings, recalled a similar number, and had similar increases in knowledge of constituents. They also reported similar or greater levels of perceived effects, and actually reduced consumption. It could be due to being primed to the purpose of the study, or sensitised to the warnings by being interviewed about them at baseline, but why this would lead to behaviour change and no change in attitude is not clear. Caution needs to be taken in interpreting the effects when the results were not consistent.

One striking finding was that smokers were far more likely to agree that smoking is addictive than to agree that it is harmful, and far more thought it was addictive than thought it was enjoyable. This pattern is consistent with a view of smokers, consciously in the grip of an addiction that has ceased to give much pleasure, and who underplay the personal risk smoking carries.

Critics of the new warnings have argued that the public already knows about the dangers of smoking, and as a result, stronger warnings are unnecessary. It is true that in Australia almost everybody has heard about dangers of smoking (as can be inferred from data in this paper) but it does not mean that they know and believe all the information that is central to making rational decisions about whether or not to smoke. The data clearly indicate that what knowledge they have is not very salient (uppermost in their minds), or there is a reluctance to admit it, or both. There appear to be large gaps in the knowledge of many.

One limitation of this study was that we did not study effects on teenagers who are susceptible to taking up smoking. We think negative effects are unlikely. Young people (admittedly all were 18 years of age or older in this study) increased their knowledge as much as older respondents, but from a higher baseline. The data are consistent with the warnings discouraging smoking in young people (albeit perhaps no more than others).

Further research is needed to explore longer term effects of the new warnings. Data on recall of the old warnings ${ }^{1}$ suggest that we might expect little or no extra recall with time. Research on warnings on alcoholic products in the United States suggests heightened awareness and caution regarding the hazards of -1 alcohol six months after warnings were $\frac{O}{0}$ implemented, ${ }^{8}$ and following a seven-month $\bigcirc$ lag, reduced antenatal drinking among black women, ${ }^{9}$ but there is no systematic body of $\overrightarrow{\overrightarrow{0}}$ research.

Other aspects of this study reported $\stackrel{\overline{\vec{S}}}{\stackrel{9}{+}}$ elsewhere ${ }^{10}$ show that the prevalence of foregoing cigarettes as a result of noticing the $\frac{\bar{\sigma}}{\bar{D}}$ warnings increased following the introduction $\frac{\bar{\sigma}}{\vec{\sigma}}$ of the new warnings. The increase was found in $\stackrel{\mathbb{Q}}{\Omega}$ both cross-sectional and longitudinal samples. क Further, foregoing cigarettes as a result of $\overrightarrow{0}$ noticing the old warnings at baseline was predictive of having quit by the time of the $\vec{\omega}$ follow-up survey. A plausible case can be made $\stackrel{\circ}{\circ}$ for the warnings having a long-term effect on $\sigma$ behaviour; however, at this point such effects have not been demonstrated convincingly.

In summary, the new Australian health warn- 0 ings on cigarette packs are an important advance on previous warning systems in that they have $\vec{\nabla}$ clearly improved community knowledge rel- $\stackrel{\mathbb{D}}{\varnothing}$ evant to an assessment of the risks associated $\frac{\mathbb{}}{3}$ with smoking and have increased the salience of $\underset{\mathbb{D}}{ }$ knowledge of health consequences. This improved knowledge base should help consum- $\emptyset$ ers to make more informed decisions. It is reasonable to presume that stronger warnings introduced in other countries will have similar benefits to those found here. The increased size $\bar{\partial}$ of the new warnings are also more congruent with the risks associated with smoking, although $\stackrel{\mathbb{Q}}{\varrho}$ arguably they would need to be even larger than $\overrightarrow{\hat{O}}$ the pack to begin to mirror the true levels of risk.

This research was funded under a contract from the Australian Commonwealth Department of Human Services and Health, and is based on an unpublished report to the Commonwealth.

1 Centre for Behavioural Research in Cancer. Health warnings and contents labeling on tobacco products. Carlton South, Victoria: Centre for Behavioural Research in Cancer, 1992.

2 Consumers International. Promoting the rights of consumers worldwide. London: Consumers International.

3 Hill D. New cigarette packet warnings: are they getting through? Med $\mathscr{f}$ A ust 1988;148:478-80.

4 Borland R, Hill D. The path to Australia's new health warnings on tobacco products. Addiction 1997;92:1151-7.

5 US Department of Health and Human Services. Reducing the health consequences of smoking: 25 years of progress. $A$ report of the Surgeon General, 1989. Rockville, Maryland: D Public Health Service, Centers for Disease Control, Office 을 on Smoking and Health, 1989. (DHHS Publication No (CDC) 89-8411.)

6 Cohen, JB. Smokers knowledge and understanding of advertised tar numbers: health policy implications. Am $\mathcal{F} \mathrm{N}$
Public Health 1996;86:18-24.

7 Walker N. Health warnings on Australian cigarettes. Perth, $\mathcal{W}$ Australia: Australian Council on Smoking and Health,

8 Kaskutas L \& Greenfield TK. First effects of warning labels on alcoholic beverage containers. Drug Alcohol Depend 1992;31:1-14.

9 Hankin JR, Sloan JJ, Firestone IJ, Ager JW, Sokol RJ, Marten SS. A time series analysis of the impact of the alcohol warning label on antenatal drinking. Alcohol Clin Exp Res 1993;17:284-9.

10 Borland $\mathrm{R}$. Tobacco health warnings and smoking-related cognitions and behaviour. Addiction 1997;92:1427-35. 